\title{
Noves tecnologies d'innovació democràtica
}

\author{
Marc Grau i Solés \\ Centre d'Estudis d'Innovació i Comunicació Política \\ marc.grau@argumenta.org
}

\section{Els beneficis de la participació ciutadana}

La participació ciutadana és un dels conceptes més habituals i un dels objectius principals en la majoria d'agendes polítiques al nostre país. En els darrers anys, aquest concepte ha deixat de voler dir només democratitzar les decisions públiques, per passar a ser entès també com a una forma de governar, un ingredient imprescindible en moltes polítiques públiques i una eina efectiva de gestió pública que permet acostar la política al ciutadà, legitimar els dirigents i augmentar la confiança del ciutadà envers seu.

La participació ciutadana, per a la ciutadania, és l'oportunitat d'una participació que va més enllà d'anar a votar periòdicament i l'habilitació d'un canal per a la implicació en les qüestions públiques i per a la transformació i superació de conflictes, gràcies a la possibilitat d'intervenir i col-laborar en les diverses fases de les polítiques públiques. Però, a més, la participació ciutadana, des de la perspectiva dels que avui gairebé disposen del monopoli d'oferir-ne oportunitats, les administracions públiques, significa la possibilitat de construir aliances amb la societat, per a l'assoliment d'objectius comuns. Si es tenen en compte les opinions i la potencialitat de tothom, participació ciutadana vol dir decisions de més qualitat, més eficàcia en l'implementació de polítiques i més capacitat de gestió.

Així, com s'ha anat demostrant en els darrers anys i destaca el catedràtic Joan Subirats $(2001)^{1}$ en un dels seus articles, "eficiència i participació no són contradictòries, sinó absolutament complementàries, i cada vegada s'aniran convertint en més i més inseparables". Cal tenir en compte, a més, que determinades qüestions o conflictes polítics, com el debat entorn a l'ordenació i futur del territori o l'ús de recursos limitats, reclamen l'interès, la participació, la implicació i el compromís de bona part de la ciutadania. I, per tant, el principal objectiu i repte de les actuals administracions hauria de ser aconseguir animar, habilitar i convidar a la ciutadania a la participació política per tal d'assegurar la presència de la màxima pluralitat d'opinions i del major nombre possible de ciutadans. Per tal que, així, els beneficis -per a tots- fossin el major possible. És més, tenint en compte també que "quan parlem de participació no parlem només dels interessos afectats, o d'aquells grups o col-lectius més organitzats i acostumats a mobilitzar-se, sinó del conjunt de la població afectada

\footnotetext{
${ }^{1}$ Subirats, Joan (2001). Nuevos mecanismos participativos y democracia: promesas y amenazas. A Font
} (ed) (2001): Ciudadanos y decisiones públicas, Ariel. 
directament o indirectament per la decisió. I això vol dir trobar mecanismes per aconseguir aquesta implicació social àmplia" (Subirats, 2001).

No obstant, la participació té costos, no només per a les administracions, també per als ciutadans. Cal ser conscients que per a participar calen determinats recursos, actituds o oportunitats relacionals. Una llibertat efectiva, una igualtat d'oportunitats per a la participació, reclama una mínima igualtat en termes de recursos per a la participació. I no tothom disposa d'aquests requisits, desigualment distribuïts en la societat. Al mateix temps, però, la millor i, potser, l'única forma d'adquirir aquests recursos és a través de la pròpia participació política. Per tant, l'única solució sembla idear mecanismes i espais en els que tothom pugui dialogar, deliberar, i en els quals, tot participant, es puguin adquirir els recursos i les actituds necessàries per a la participació política, com poden ser per exemple, la capacitat de dialogar o de defensar els propis interessos i punts de vista. O sigui, vol dir habilitar espais oberts i accessibles a tothom i poc exigents en termes de recursos i actituds, on els participants puguin anar adquirint aquests recursos i habilitats necessaris per a participar en altres espais de participació més exigents.

\section{Els dilemes d'una relació inevitable}

Com hem comentat en l'apartat anterior, hi haurà participació ciutadana, nombrosa i de qualitat, per tant, si se sap habilitar a la ciutadania, facilitant els recursos i les actituds necessàries, oferint-ne oportunitats. La clau és, ara, cercar els instruments que facilitin aquesta participació i "saber quins mecanismes poden contribuir a això sense carregar en excés (de costos de temps i de transacció) les ja cansades espatlles de la ciutadania" (Subirats 2002) ${ }^{2}$.

En l'article de Joan Subirats titulat Els dilemes d'una relació inevitable. Innovació democràtica i tecnologies de la informació i de la comunicació, el catedràtic de Ciència Política ens exposa i analitza els potencials de les TIC com a recurs per a facilitar l'accés de la ciutadania a les activitats dels seus governs i en processos de participació ciutadana. Segons ell, l'ús de les TIC com a suport per a reforçar les oportunitats de participació política pot arribar a ser molt significatiu, no obstant, ens avisa, també, del fet que la seva forma d'operar i la del sistema polític no semblen ser massa coincidents. Oposat a la forma digital de raonar -simple i binària-, "davant del dilema de $A \circ B$, (el raonament polític) pot buscar les respostes en tots dos o en cap, o en aquests no són les respostes al problema, o fins i tot un aquest no és el problema". I la política és i ha de seguir sent un escenari de deliberació, amb espai per als matisos.

Subirats inicia el seu article amb una declaració de John Daniel, rector de l'Open University, en una conferència sobre la nova societat de la informació, on afirmà: "Senyores i senyors, les noves tecnologies són la resposta. Quina era la pregunta?". Una bona forma, aquesta, d'expressar les grans expectatives generades davant les interessants possibilitats que planteja l'ús de les noves tecnologies de la informació i la comunicació (TIC) i el desconcert, al mateix temps, sobre els objectius i els impactes reals del seu ús. Segons Subirats, una pregunta útil que ens hauríem de formular, aquí, és

2 Subirats, Joan. (2002). Els dilemes d'una relació inevitable. Innovació democràtica i tecnologies de la informació i de la comunicació. En Cairo Carou, Heriberto (ed.). Democràcia Digital. Límits i oportunitats. $1^{\mathrm{a}}$ ed. Trotta. 
per a què les podem fer servir $\mathrm{o}$, sobretot, en què ens poden ajudar. $\mathrm{O}$, en les seves mateixes paraules, hauríem de pensar en els problemes que avui tenim plantejats i en les utilitats potencials $i$ reals d'aquestes TIC. I ell mateix, en l'article, ens en destaca un de prou suggerent: el fenomen percebut en els darrers anys de desafecció i allunyament dels ciutadans cap als actors i institucions polítiques, "desafecció i desconnexió de grups, comunitats i individus en relació a les institucions democràtiques representatives, vistes com aliens a les seves vides socials". De fet, en aquest sentit, un fenomen que explica, segons ell, al mateix temps, la ja comentada proliferació d'experiències participatives, lligada a la insuficiència de les vies tradicionals de participació.

L'escenari públic en el que ens trobem actualment es caracteritza per una major complexitat de les nostres societats, múltiples canvis han afectat totes les esferes de la nostra vida, també en la participació política, tal i com hem destacat, amb un descens de la confiança dels ciutadans en relació a les seves institucions i una disminució de la participació a través dels mecanismes convencionals. Les eleccions, com a sistema de participació, són un mecanisme que ofereix una informació molt minsa i acotada en el temps als ciutadans sobre les polítiques que aplicaran els seus representants. Els ciutadans no poden ni decidir ni controlar i són relegats a un rol passiu, sovint, només com articuladors de demandes als governs. I aquesta poca capacitat de participació política dels individus en la democràcia representativa, provoca, a més, com a reacció, que molts ciutadans es desentenguin de la política.

Entre les principals conseqüències dels nombrosos canvis que destaca Subirats en l'article, la desaparició de l'espai per a una esfera pública de debat i opinió es presenta, segons la meva opinió, com un repte important que reclamaria, potser aquest cop, una resposta de les ja comentades suggerents possibilitats que presenta l'ús de les TIC. En aquest sentit, no hi ha solucions ni respostes clares, diu Subirats (2001), però, si convé no oblidar que determinades apostes són imprescindibles:

"tenim la convicció que només construint mecanismes democràtics que permetin decidir amb rapidesa i eficàcia, però també que permetin implicar la ciutadania, escoltar les seves opinions i tenir-les en compte en les decisions a prendre, serà possible mantenir la vitalitat d'unes institucions democràtiques que s'han anat convertint en material sensible"

L'article de Subirats no ens permet assegurar, avui, si les TIC oferiran una resposta a aquests o als altres problemes o conflictes que se'ns plantegen, però, d'una forma o d'una altra, reconeix, segur que hi tenen i hi mantindran un paper central. I és que, com diu, "si bé continua sent cert que tots els ciutadans de cada país no poden trobar-se cara a cara, si és possible que puguin comunicar-se a distància a través de les xarxes que ofereixen les TIC".

\section{Noves tecnologies per a la innovació democràtica}

En els darrers anys han aparegut en el nostre país diverses propostes de suport a la participació ciutadana basades en recursos, sobretot, que es desenvolupen a través d'internet. Un dels primers fou Democràcia Web, una experiència de democràcia electrònica impulsada per la Fundació Jaume Bofill i amb el suport del Parlament de Catalunya. Amb l'objectiu de l'apropar el Parlament a la societat catalana i en els processos de formació d'opinions i voluntats polítiques, fomentant i facilitant la participació ciutadana, aquesta experiència permet accedir a un espai de debat sobre les qüestions que es discuteixen al Parlament. 
D'altra banda, cal destacar especialment, aquí, l'aparició el 2002 de Delibera, un sistema format per un conjunt d'eines i metodologies que s'apliquen tant en reunions presencials com en fòrums de deliberació a distància via Internet. Un sistema integral de participació multilingüe que l'empresa Delibera - Serveis de Participació Interactiva desenvolupà per ajudar tot tipus d'organitzacions a fer fòrums per deliberar, prioritzar o consensuar posicions, per preparar reunions o per elaborar manifests o plans d'acció. El sistema Delibera ajuda a valorar pros i contres, i a deliberar, col-lectivament, a partir d'unes icones de colors que permeten expressar fàcilment i visualment la posició i la valoració de cadascú sobre qualsevol tema a tractar.

En tercer lloc, voldria destacar l'eina tecnològica Consensus, dissenyada per facilitar i impulsar la informació, la comunicació i la participació ciutadana a través d'Internet en el món local, i utilitzada per més d'una vintena de municipis, des de 2004, com a espai de difusió dels seus processos participatius. Consensus ha estat impulsat per tres institucions catalanes (la Fundació Jaume Bofill, I'Institut Català de Tecnologia i el Consorci Localret) i per 12 ajuntaments catalans que han finançat una part del projecte, amb el suport del Ministeri de Ciència i Tecnologia del l'Estat espanyol i del Departament de Governació i Administracions Públiques de la Generalitat de Catalunya. Aquesta eina electrònica permet als ciutadans informar-se, debatre a través de fòrums amb altres ciutadans i responsables polítics o activitats com enviar cartes, respondre qüestionaris o participar en recollides de signatures.

Per últim, voldríem explicar i descriure un quart i darrer recurs tecnològic: Argumenta, aplicació electrònica de participació deliberativa, un projecte impulsat pel Centre d'Estudis d'Innovació i Comunicació Política que ofereix, a la disposició de la ciutadania, un petit espai públic virtual i d'encontre per al debat ciutadà i l'articulació i el reforçament comunitari. L'Argumenta, reconeixent i fomentant un paper clau dels arguments en els processos de decisió política, és un canal de participació política, un instrument de participació ciutadana, una eina virtual que facilita i estructura la deliberació i el debat en el marc de processos participatius, permet la celebració de consultes o referèndums a través de la xarxa i la realització de tècniques i dinàmiques participatives 0 de superació de conflictes.

Un recurs que entén el diàleg entre ciutadans no només com el principal vincle d'unió entre les persones d'una societat, sinó com la forma lògica de resoldre els conflictes que en sorgeixin i d'afrontar els reptes que es presentin i ingredient imprescindible en qualsevol procés de presa de decisió pública.

D'altra banda, una societat civil articulada i amb recursos o oportunitats per a la deliberació vol dir trencar els monopolis interpretatius oficials respecte els problemes i conflictes, al mateix temps que assolim una opinió pública més coherent i sòlida i uns resultats de les seves decisions i accions més justs i raonables. Així, aquesta aplicació electrònica de participació deliberativa també és una eina útil i suggerent per al foment del debat intern en el si de col-lectius o entitats i permet habilitar a altres actors, a banda de les administracions, a oferir oportunitats de participació ciutadana, contribuint a la seva sofisticació institucional i en la disposició dels recursos necessaris, tot avançant també cap a un escenari d'oportunitats de participació ciutadana més descentralitzat i menys depenent d'una única font.

Argumenta és una aplicació electrònica a la disposició dels municipis o de les entitats, però, sobretot, dels arguments, l'ingredient clau de la deliberació, per a qualsevol procés de participació ciutadana o 
de decisió política de qualitat; un pas endavant cap a una democràcia més participativa, relacional i deliberativa.

\section{La participació deliberativa}

En relació amb el conjunt d'aspectes que hem anat comentat en aquestes pàgines, cal destacar com l'aparell conceptual que envolta la democràcia deliberativa es presenta com una proposta normativa molt suggerent que pot esdevenir un recurs fonamental per enfortir la legitimitat de les institucions polítiques actuals i avançar cap a una democràcia de major qualitat. La perspectiva deliberativa -com també fan recursos electrònics que hem comentat com l'aplicació Argumenta o les eines Deliberasitua en un pla central l'element argumentatiu i és una condició indispensable, segons Subirats (2002), per a qualsevol intent d'incorporació de les TIC com a suport en processos de presa de decisions:

"tota incorporació de les TIC als processos de presa de decisions públiques, hauria de tenir en compte aquest profund caràcter deliberatiu de la democràcia. De no ser així, podria passar que aquestes decisions poguessin ser notablement inconsistents entre si, o bé que estiguessin massa afectades per situacions emocionals conjunturals. Per tant, hauríem de dirigir-nos cap a perspectives en les que fora possible o imaginable utilitzar els potencials comunicatius i de presa de decisions collectives que les TIC sens dubte presenten (i que han estat provats en contextos privats o organitzacionals), sense que això fes perdre capacitat i qualitat deliberativa a tot el nou procés decisional inspirat en un acostament als valors d'una democràcia directa que sempre ha estat vista com a desitjable, però no viable"

Com declarà Martí Olivella en el II Congrés català de Gestió Pública, si participar no és sols anar a votar, si la imposició en una democràcia és inacceptable i l'agregació de vots configura guanyadors i perdedors, la deliberació esdevé el nou repte d'una democràcia de més qualitat. Potenciar la deliberació hauria de ser un procediment habitual en la vida quotidiana per decidir amb justícia en qüestions vitals que afecten a tots. Potenciar el costum d'un diàleg entre persones disposades a argumentar i a deixar-se convèncer amb arguments i situar la deliberació com a una característica consubstancial i imprescindible en qualsevol procés de participació ciutadana de qualitat.

En democràcia, la participació ciutadana no vol dir només decidir, sinó també la possibilitat d'aportar raons en el marc d'un debat. I implica, també, que les majories siguin capaces d'escoltar els arguments de les minories. Així, un procés deliberatiu de qualitat enforteix la democràcia. Una qualitat de la democràcia que cal entendre com a atribut del propi procés polític. Si s'ha pres una decisió després d'un procés de deliberació de qualitat, un procés d'informació i de debat, un procés en el que s'ha permès, habilitat i convidat a la ciutadania a participar -amb transparència i respecte per a tots els arguments- aquella decisió tindrà una major qualitat democràtica, major que una altra que només disposi de la legalitat a favor seu i estigui imposada per uns pocs; una decisió o acció és democràtica, en definitiva, no només perquè provingui d'un òrgan democràtic, sinó també per tenir un funcionament democràtic.

Com explica Olivella, deliberar, en el marc d'un procés participatiu, és la dinàmica anterior a decidir, a votar o a actuar, és el temps dedicat a escoltar i contrastar opinions, a estudiar pros i contres. Com el detectiu de les novel.les que investiga un assassinat i no resol el cas al trobar la primera pista o des de casa sense investigar, la deliberació pot ser la construcció discursiva d'un fet o conflicte en el marc 
d'una societat, l'exposició col-lectiva d'arguments que ens permeten entendre o prendre una decisió davant d'un fet públic.

La participació deliberativa ens permet revelar informació de la ciutadania, mostrar opinions o preferències que completen o corregeixen informacions obtingudes a través de les formes tradicionals de participació ciutadana. I, a més, l'encontre i el contacte entre els arguments dels diversos ciutadans, la construcció col-lectiva de posicionaments i en definitiva, l'ambient deliberatiu, té un efecte civilitzador en els participants que han de qüestionar els propis interessos i adoptar una actitud responsable, honesta, objectiva i amb voluntat i vocació de consens. Fruït del diàleg ciutadà, estructurat $\mathrm{i}$ fonamentat en els arguments, els participants enriqueixen els propis posicionaments $\mathrm{i}$ coneixen, ordenen, justifiquen millor $\mathrm{o}$, fins $\mathrm{i}$ tot, modifiquen les seves preferències.

La deliberació és una forma superior a la negociació, no és un joc de suma zero. La deliberació és reflexió, una forma per a arribar a decisions de consens en el procés de les quals ningú es limita a defensar una determinada postura, sinó que entre tots els participants intenten determinar i analitzar els arguments favorables o contraris de qualsevol possible decisió o posicionament. La deliberació crea valor entre els participants, busca la decisió més justa i més legitimada en cada cas, i troba, com a mínim, la solució més acceptada pel conjunt dels que participen. La deliberació, l'intercanvi d'arguments, permet la relativització i, al mateix temps, la construcció de veritats, de les veritats individuals, però també $i$, sobretot, de veritats col-lectives, del sentir col-lectiu davant un fet o conflicte d'una societat, un sentit comú fet de raons, ple de contingut, farcit entre tots d'arguments i consensuat, que esdevé bon sentit per a tothom.

La participació deliberativa parteix del reconeixement d'un paper central del llenguatge i la comunicació en la política, en la construcció de les pròpies opinions o en la resta d'aspectes de les nostres vides. Quan no hi ha veritats absolutes, quan tenir la raó sempre és relatiu, quan no hi ha solucions per tot, el que es necessiten són raons, no hi ha res millor que cercar entre tots arguments. La participació deliberativa -i aplicacions com l'Argumenta- permeten i fomenten la reflexió col-lectiva i estructuren un cos d'arguments i raons que ens permeten entendre i afrontar qüestions o conflictes públics.

La deliberació ens disposa a aconseguir que es faci col-lectivament, allò que fem individualment quan diem que pensem o reflexionem. On el tot sempre és més que la suma de les parts, unes parts que aporten els seus ingredients a un plat cuinat col-lectivament. I com en el cas del detectiu que ha de trobar totes les proves possibles per entendre el seu cas, no hi pot haver cap plat sense tots els ingredients.

Si les qüestions o conflictes públics són col·lectius, s'han d'entendre col·lectivament i s'han d'afrontar col-lectivament. I si estem parlant d'actituds i opinions, si aquests són els ingredients que enriquiran el plat, amb coherència amb el que són, maneres de parlar a partir de les quals fem saber als altres la nostra posició davant determinats fets o conflictes, no hi ha millor forma de cuinar-ho que oferint bones oportunitats a la ciutadania per al debat i la deliberació.

Davant la ja comentada necessitat de més espais per al debat ciutadà i la conveniència de més oportunitats de participació ciutadana, la deliberació sembla la millor forma de canalitzar la pluralitat de punts de vista que existeixen davant qualsevol qüestió a debatre en un col-lectiu de persones. El que cal són escenaris i instruments a la disposició dels ciutadans que els facilitin els recursos, el temps i l'estructura per a la trobada còmode, funcional, oberta i transparent en l'intercanvi, la contraposició i la construcció d'opinions i posicionaments. 


\section{Apunts finals: la deliberació com a requisit per a una millor gestió pública}

Com ja hem anat comentant en aquestes pàgines al parlar dels beneficis i les condicions necessàries de la participació ciutadana, per a assolir processos i canals de deliberació de qualitat són necessaris espais de debat, i si aquest vol ser constructiu, ha d'estar ordenat i estructurat. Els debats han de ser discussions argumentades, intercanvis de raons, exposicions d'arguments favorables o contraris en relació a una determinada qüestió o conflicte. Només mitjançant un debat estructurat a partir d'arguments, com passa amb les peces per construir un trencaclosques, s'assoleixen tots els detalls del mapa -a partir de la recerca, l'intercanvi i la contraposició dels arguments- per a poder conèixer $\mathrm{i}$ entendre la qüestió debatuda.

No obstant, sense deliberació difícilment tindrem una participació ciutadana de qualitat, i sense participació no hi ha complicitat, no hi ha aliança amb la societat, no hi ha un reforçament de les capacitats de la gestió pública ni de la seva legitimitat.

Si els ciutadans no gaudeixen d'una gestió pública transparent de les decisions que els afecten, no poden prendre part en els afers públics ni intervenir en els conflictes inherents en unes societats, les actuals, cada cop de major complexitat, el resultat és la desconfiança i l'allunyament de la ciutadania respecte els seus representants, amb la conseqüent pèrdua de suport $\mathrm{i}$ deslegitimació de les institucions polítiques actuals.

Amb tot, una participació ciutadana de qualitat, vol dir també una gestió pública que sap acostar-se al ciutadà, que es guanya la seva confiança, permetent-li generar aliances amb la societat i un compromís cívic entre els ciutadans.

Els reptes i conflictes d'unes societats cada vegada més riques i complexes, reclamen els beneficis de la intervenció en els processos de deliberació i decisió pública, com en la resta de fases de les polítiques públiques, de tots aquells actors que puguin aportar visions o recursos al procés. Una gestió pública recolzada per i -sobretot- en la participació ciutadana és una gestió més transparent i idònia per a la transformació i superació de conflictes. Conflictes, provocats per la creixent complexitat de les nostres societats i que, més que ser ignorants, s'han de plantejar com a oportunitats per avançar. Aquesta, com hem dit, és una gestió pública transparent i transformadora de conflictes, però també més propera al ciutadà i amb major qualitat i capacitat d'acció o de decisió

\section{Formato de citación}

Grau i Solés, Marc. (2006). Noves tecnologies d'innovació democràtica. Athenea Digital, 10, 203-210. Disponible en http://antalya.uab.es/athenea/num10/GrauM.pdf.

Marc Grau i Solés. Politòleg, cofundador i director del Centre d'Estudis d'Innovació i Comunicació Política, i ideador i impulsor d'Argumenta, aplicació electrònica de participació Deliberativa 


\section{(C)}

Este texto está protegido por una licencia Creative Commons.

Usted es libre de copiar, distribuir y comunicar públicamente la obra bajo las siguientes condiciones:

Reconocimiento: Debe reconocer y citar al autor original.

No comercial. No puede utilizar esta obra para fines comerciales.

Sin obras derivadas. No se puede alterar, transformar, o generar una obra derivada a partir de esta obra.

\section{$\underline{\text { Resumen de licencia }}$}

$\underline{\text { Texto completo de la licencia }}$ 